\title{
Falibras Translator: Towards More Health Care Humanization for Deaf People
}

\author{
Vitor Marcolino ${ }^{1}$, Natália M. Franco ${ }^{1,3}$, Patrick H. Brito ${ }^{1,2}$, Luis C. Coradine ${ }^{1}$ \\ ${ }^{1}$ Computing Institute Federal University of Alagoas Maceió, Brazil \\ ${ }^{2}$ Computer Science Course Federal University of Alagoas. Arapiraca, Brazil \\ ${ }^{3}$ Informatics Center Federal University of Pernambuco. Recife, Brazil \\ \{vitor.marcolino, lccoral\}@gmail.com, patrick.brito@gmail.com, \\ nmf@cin.ufpe.br
}

\begin{abstract}
This work presents Falibras, a translation system between Portuguese and Brazilian Sign Language (LIBRAS) that aims to help both, deaf people and hearers, in trying to communicate. Falibras offers an important tool to provide easy communication and more humanization of health care for deaf people. This paper presents some of the re-engineered artifacts of the Falibras system. Moreover, a discussion about its applicability in e-Health is also presented. Among its main applications, this system supports language learning, both sign and writing language, autonomy for deaf people and humanization in health care. Falibras also gives the possibility of generalizing the translation process in order to allow the translation from any written language to any target language (written, spoken or signaled). Thus, the translation mechanism does not limit the languages involved.
\end{abstract}

Keywords. Assistive Technology; eHealth; Deaf People; Automatic Translation; Sign Language; Communication.

\section{Introduction}

People with hearing loss (PHL) demand for access to information resources, particularly resources related to the communication and educational domain. In order to provide legal support for the PHL in 2002 was enacted Law No. 10,436 known as LIBRAS Act. The LIBRAS Act ensures, among other things, the right to education and health care of deaf people, the presence of interpreters in the classroom and in the healthcare services, and the inclusion of Brazilian Sign Language (LIBRAS) as a compulsory curriculum subject in courses for training teachers and health professionals.

The LIBRAS Act also establishes that Brazil is a bilingual country with two official languages: Portuguese and LIBRAS. According to Ronice Müller [QUADROS 2006], the bilingual context of the deaf people in Brazil is configured on the coexistence of LIBRAS and Portuguese. In this case, it is not enough to decide if either one or another language will become part of the educational context, but, allow the coexistence of the two languages. We highlight the different functions that these two languages have 
in the daily life of deaf people. The written languages (e.g., Portuguese) should always be seen as the second language of the deaf community, and the sign language (e.g., LIBRAS) the base language for developing thinking and language writing mode acquisition. Deaf people are more likely to absorb information through the visualgestural channel, as LIBRAS does. But, it is important to learn the written languages to absorb general information (e.g., text, signpost), gestures or lip-reading to communicate with hearers that do not know sign language. This way, deaf people can be better socially included in our society.

Despite writing be a facilitator in the communication with some deaf people, it is not much helpful to the pre-linguistic deaf, that is, those who were deaf before the acquisition of oral language [BARNETT 1999]. Moreover, deaf people who communicate only with sign language can be compared with foreigns which cannot speak Portuguese. They could be seen as foreigns in its own country. Deaf people usually complain about difficulty in reading and producing texts [CHAVEIRO 2009] [COSTA 2009]. These difficulties highlight the importance of the problem related to communication with hearers and the social and cultural inclusion of deaf people in society.

Interpersonal communication problems are present throughout the health system and become more significant when involving language barriers and culture. The meeting between health professionals and deaf patients is often marked by barriers and difficulty in communication [FOLKINS 2005]. These communication barriers can hinder the necessary bond that needs to be established, lowering the quality of provided assistance. Furthermore, it may interfere with diagnosis and treatment [CHAVEIRO 2009].

Deaf people cannot conduce a medical appointment without an interpreter if the health professional does not know sign language. It is important to mention that the dialogue between health professional and patient cannot substitute the clinical exam, but it can provide more informations about the diagnosis and the treatment. The presence of a third person (e.g., interpreters or relatives) in a medical appointment can, on one hand, facilitate the communication, but, on the other hand, can lead to lack of privacy and patient autonomy [COSTA 2009].

Moreover, the direct communication can approach health professionals and patients, enabling an exchange space for learning on both sides. The patient receiving the simplified explanation learns, in turn, health professionals also learn to communicate with the deaf person. Hearers have a lot of information about diseases, preventions and treatments. But, we do not know how much of this information is available for deaf people. This way, this exchange space can overcome this lack and create many health knowledge disseminators in the deaf community. Besides that, the direct dialogue brings more humanization and improves the quality of health care.

In order to facilitate communication between deaf and hearing people, and support the training of interpreters and health professionals, appeared in 2002 a project called Falibras [CORADINE 2002]. Since its inception, the Falibras project aims to translate the sound captured by the computer microphone, in LIBRAS animations. The Falibras initiative stimulated a wide range of new multimedia tools designed to meet the 
specific audience, especially with regard to the communication and teaching-learning process [BREDA 2009] [CORADINE 2007] [FRANCO 2013]. So that, Falibras can be used for training both, health professionals in learning LIBRAS and deaf people in learning the written language.

Despite the preliminary results of the project have been positive [BREDA 2009] [CORADINE 2007] [FRANCO 2013], important limitations were perceived to undermine the adoption of the Falibras system in a large scale scenario. Examples of such limitations are: (1) the existence of grammatical variations in the structure of LIBRAS sentences, in different parts of Brazil; (2) difficult to adapt the system to other input (writing) languages and output (signaling) languages; (3) lack of integration with web browsers; and (4) practical difficulty in the production of new signs.

In order to improve Falibras we have carried out a re-engineering process to improve its software architecture and to make its translation process more flexible and precise. In addition to improving the accuracy of the translation and a better linguistic flexibility, the new features of Falibras system aimed at three major objectives: (1) integration with the web browser; (2) improved support for training interpreters; and (3) integration with SinaLibras 3D [AMARAL 2011], which generates LIBRAS sign animations in real time. This article presents this reengineering regarding its componentbased software architecture, its translation engine, and its new features and applicability.

\section{The Falibras System}

Falibras was proposed as a machine translation system between Portuguese (source) and Brazilian Sign Language (LIBRAS) (target). In other words, Falibras translate texts in Portuguese to LIBRAS in the lively gestured form. It has been developed since 2002 with a pedagogical finality seeking educational inclusion of the Deaf community in Brazil [CORADINE 2002, 2007]. In this way, Falibras has potential as an assistance tool to promote easy communication and to facilitate LIBRAS learning, mainly, to people who need interact with deaf people.

Since the first version of Falibras, the text (obtained via speech or directly typed) is handled by the interpreter module that performed direct interpretation of words and small expressions. This interpretation does not consider the syntactic structure nor the context of phrases [CORADINE 2002]. The second phase was marked by focusing to improve the quality of translation. The interpreter module became a lexical analyzer being improved by morphological analysis. With this, the Falibras system is able to identify the grammatical classification (e.g., noun, verb, adjective, adverb) and flexions (e.g., tense, person, number, gender, degree) of words [CORADINE 2007]. In the third phase, the syntactic analysis began to be performed by the system. Since then it has become possible to construct a syntax tree that results in a phrase structure of LIBRAS, using translation rules for that. After that, the animations can be mounted and displayed. In addition to the existent lexical analyzer, Falibras was increased by a syntactic-graphbased parser, a context parser (to verify the noun and verbal agreement between words in the same sentence), and the LIBRAS-translation generator. 
The primary machine translation technique used was the syntactic transfer, which constructs the syntax tree from the source language grammar and maps it to a syntax tree matching the target language grammar. The language that was used to fit the syntactic and translation rules, namely, Prolog, proved to introduce restrictions on performance practices and to limit the grammar size.

Another work was developed in partnership with Federal University of Espírito Santo (UFES), known as Falibras-MT [BREDA 2009]. In this work, the translation module changed in order to adopt the translation memory mechanism. In this version of the translation module, the translation process consists on a set of queries to a database, previously populated of examples done by a human translator, which is used to translate similar excerpts, i.e. the module is an authoring one, allowing someone to edit and save segments of translation into the translation memory.

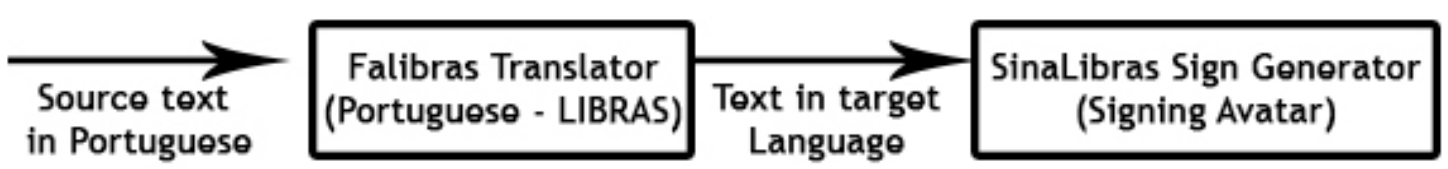

Figure 1. Integration between Translation and Sign

Before giving details about the current version of Falibras System, it is important to notice that Falibras focuses on the translation process. Although it does not consider the generation of LIBRAS signs, it allows integration with different animation modules. Figure 1 presents the two independent modules of the complete solution: Falibras System and SinaLibras 3D [AMARAL 2012].

\section{Falibras System Current Version}

The Falibras broaden to encompass web-browser environment, thus, Falibras was reengineered and new features were incorporated. Its architecture was redesigned to obtain more modular and easier to evolve representation. The new implementation emphasized the use of software components and explicit interfaces to mediate the communication among them. The four main improvements are:

\subsection{Decoupling of the LIBRAS-Animation Module}

Falibras currently has two kinds of output: 3D animation or text (sequence of glosses). The latter aims to allow easy integration to any LIBRAS-animation software. For that, as presented in Figure 1, it uses the Pipes and Filters architecture [TAYLOR 2009], 
which guarantees that the translator and animator can be executed in sequence and that the output of the translator can be supplied directly as input to the animator.

\subsection{Hybrid translation module}

Falibras has now a refactored translator module, uniting the features of two earlier versions, i.e. this new version combines syntactic transfer translation and translation memory.

Figure 2 presents the translation process of the new translator component of the Falibras system. Unlike the Falibras-MT version, after receiving input text (in the source language), the translator component initially assesses the possibility of the sentence be an exception of any rule. If not, it checks the existence of a translation segment (as a translation example) that can, per analogy, translate the text. And finally, if no rule contains neither exceptions nor rules that can infer the translation structure of the input text, the translation processes according to the default translation rules, using syntactic transfer; but now implemented in Java, no longer in Prolog.

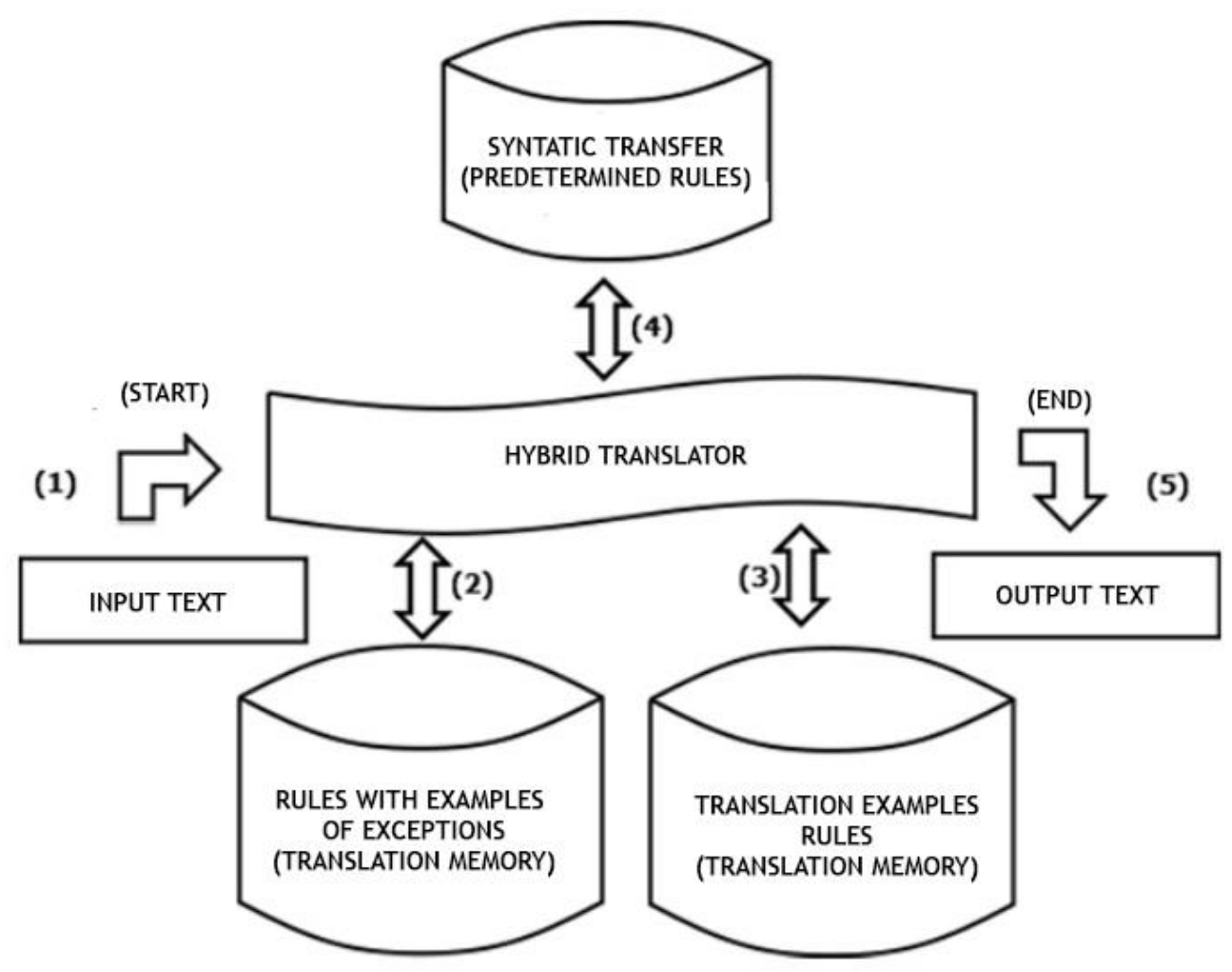

Figure 2. Translation process used by the new translator component of the Falibras system

Moreover, the form how the translation is fitted changed. The similarity comparison between the target text and the registered translation segments (examples) can be done by considering either the specific words or their morphological structure. 
For instance, it is possible to translate the sentence "she has a fever" from the segment (example) "Louis has cancer". This can be performed because the activation condition has become more flexible and may consider both specific words and several morphological elements.

Beyond the improvements in the translation process, for better accuracy and performance, this version treats elimination of ambiguity through probabilistic techniques, using a supervised learning method by Bayesian classification.

\subsection{Interpret assistance module}

It has two roles in the system: to facilitate the preparation of LIBRAS-interpreters for a specific event or subject, and to increase the translation quality of the system. This module allows the interpreter to load the text to be interpreted, check the rules of Portuguese and translation rules that are activated for each phrase. The absence of rules indicates that the interpreter may require prior preparation. Exceptions are also considered. There are two types of offered support: QuickView, which presents all information in a single screen, and Wizard mode, focused on the identification and registration of new morpho-syntactic and translation rules.

\subsection{Web accessibility module}

Its goal is facilitating the accessibility of Web content in Portuguese by the people who know LIBRAS. This tool is an add-on for Firefox browser. Figure 3 presents the display screen of the add-on, in that can be seen the clear layout and the avoidance of excessive use of the Portuguese language, preferring, instead, to make use of intuitive icons.

The module was implemented with XUL (XML User Interface Language) and uses the translation module from Falibras in a client-server architecture. To do it, an adapter was developed to encapsulate the new hybrid translation component in a servlet (server). It's used JavaScript to accomplish the communication to the browser (client).

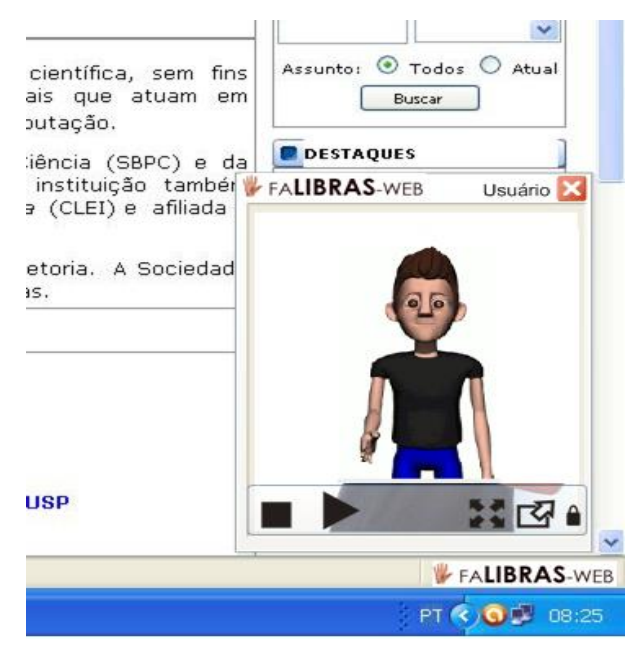

Figure 3. Display screen of Falibras-Web, where the avatar perform the signs 


\subsection{Falibras Current Architecture}

Figure 4 presents the reference architecture adopted by Falibras system, which follows a heterogeneous style that has influence of three different architectural styles [TAYLOR 2009]: Data-centric, MVC and Client-Server.

- Data-centric

It facilitates the integration between rule-generator modules and performer modules that use morpho-syntactic and translation rules.

- Model-View-Controller - MVC

It's a design pattern that allows better separation between functionalities and data, plus it separates explicitly the specific role of each component: vision (user interaction), control (business logic - translation) and model (data). This division reduces coupling and facilitates the integration of the translator with different interfaces (e.g. Desktop and Web).

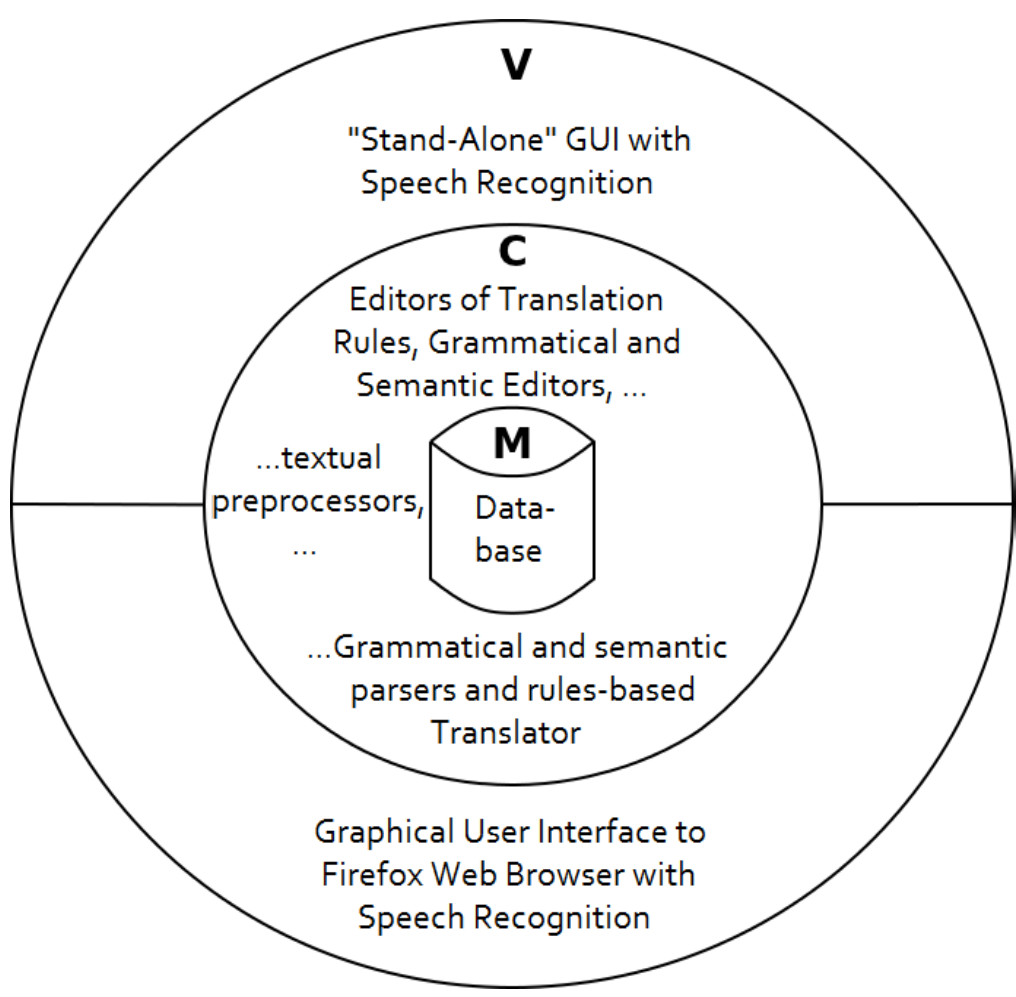

Figure 4. Reference Architecture of the Falibras System

- Client-Server

It facilitates the load distribution to multiple servers, what increases the scalability of Falibras. Figure 5 shows the internal components of the architecture. As you can see, it 
provides separation of the MVC pattern, and so it is consistent with the Figure 4. Comparing the latter two figures, it's possible to identify that the vision layer contains the graphical interfaces of the system, which can be desktop or Web. In the control layer, there are domain functionalities, such as editors of translation rules, grammatical editor, grammatical and semantic parser, spell and grammar checker, automatic text synthesizer and translator. The model layer is responsible by rules database and data persistence functionality. Hence, the user interact with the vision layer, through text format entries, which access the features of the control layer, and then, these features access the database of the model layer.

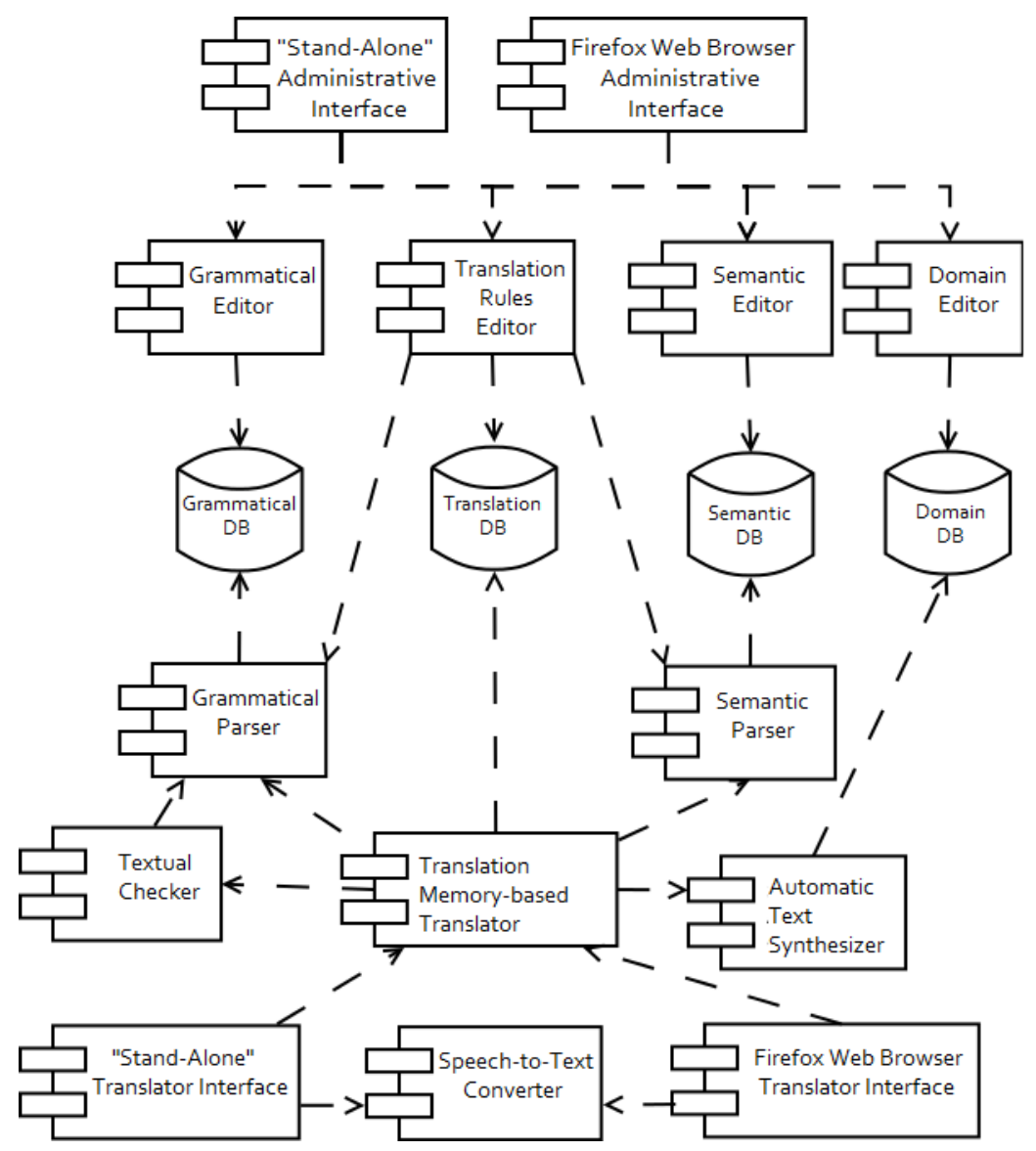

Figure 5. Architectural Elements, showing modules and its links

To process the translation request, the "translation memory-based translator" component may order orthographic and syntactic corrections of the text to be translated. These tasks are performed by the "textual corrector". After the corrections, the Translator queries to the "parser" module the classification of the words of the text according to the syntactic context of the phrase. After this analysis, the text is ready to be translated. However, in this new architecture of Falibras, the user can choose to translate either the original text or to translate an automatic generated synthesis of the text. The synthesis of the text, which is an optional step, is requested by the Translator to the "automatic text synthesizer" module. After the activities of preparing the text, the translation begins. In this process, the translation occurs phrase by phrase. The 
grammatical (morpho-syntactic) classification is requested from the Translator to the "parser" component, while the semantic classification is requested by the Translator to the "semantic parser" component. After the classification, the Translator component identifies the necessary translation rules and, by analogy, it generates the sequence of equivalent translation glosses in LIBRAS, according to the principle of translation memory. It's important to mention that the absence of translation rules is treated like a standard translation, made from syntactic translation rules implemented direct in Java.

Currently, it's being held the integration between Falibras system and SinaLibras 3D, which consists of a graphical generator of 3D animations of LIBRAS, in real time [AMARAL 2012]. The integration is based on the Pipes and Filters architectural style and it has been carried out in the context of the project $\mathrm{MCTI} / \mathrm{CNPq}$ number 458691/2013-5.

\section{Conclusion}

Communication is an essential factor to achieve the health humanization. Both deaf and health professionals need to be heard, in order to establish a dialog network to reduce distances, to connect people and to improve quality of life. With this dialog, the deaf people can ask questions and gain autonomy to discuss aspects of their own health and intimity. In this context, the Falibras system emerges as an important eHealth tool to reduce the communication barriers between these two groups (deaf and hearing people), because it is an automatic translator from the Portuguese language to the Brazilian sign language (LIBRAS). Furthermore, this translator can be extended from any written language to any target language (written, spoken or signaled).

This article presented the architectural details of Falibras, its software components and the new hybrid procedure for translation. We believe that this system has a great impact in the areas of education and health, such as: (1) facilitate communication between deaf and hearer; (2) give privacy and autonomy to deaf people; (3) humanize healthcare of deaf patients; (4) promote both learning, LIBRAS by the hearer and Portuguese by the deaf; (5) promote the development of language, thought and the deaf individual; and (6) facilitate the inclusion of the deaf people in the social environment.

In its current stage, Falibras system is able to translate from written or spoken language to the sign language. This allows that the deaf people understand what the hearer wants to say, but, when the deaf person tries to communicate, the hearer cannot understand the deaf signals. With this in mind, as a future work we intend to cover the way back, from sign language to written or spoken language. For now, Falibras users (e.g., deaf and hearer) can develop a methodology of asking binary questions (e.g., Yes or No) to facilitate the communication.

\section{References}

AMARAL, W. M. "Sistema de transcrição da língua brasileira de sinais voltado à produção de conteúdo sinalizado por avatares 3D", Tese de Doutorado, Faculdade de Engenharia Elétrica e de Computação, University of Campinas, Campinas, SP, Brasil, setembro, 2012 
AMARAL, W. M.; DE MARTINO, J. M.; ANGARE, L. M. G. "Sign Language 3D Virtual Agent", 5th IMSCI'11. Vol. 1. no 1. pp. 93 - 97, 2011.

BARNETT, S. "Clinical and cultural issues in caring for deaf people", Fam Med, pp. 17-22, 1999.

BREDA, W. L.; CAON, D. R. S.; BRITO, P. H. S.; TAVARES, O. L.; MENEZES, C.; CORADINE, L. C.; ALBUQUERQUE, F. C. "SOTAC: A Software for KnowledgeBased Automatic Translation", 9th IFIP WCCE. Vol. 3. no 1. pp. 31 - 40, 2009.

BREDA; W. L.; Caon; DANIEL, R. S.; BRITO, P. H. S.; TAVARES, O. L.; MENEZES; C. S.; CORADINE, L. C.; ALBUQUERQUE, F. C. "SOTAC: A Software for Knowledge-Based Automatic Translation". In: The 9th IFIP World Conference on Computers in Education, 2009, Bento Gonçalves/RS. Proceedings of the 9th IFIP World Conference on Computers in Education, 2009. v. 1. p. 1-10.

CHAVEIRO, N.; PORTO, C. C.; BARBOSA, M. A. "Relação do paciente surdo com o médico", Revista Brasileira de Otorrinolaringologia, São Paulo, v. 75, n. 1, fev. 2009.

CORADINE, L. C.; ALBUQUERQUE, F. C.; BRITO, P. H. S.; SILVA, R. L.; SILVA, T. F. L. "Falibras System: animated interpretation in LIBRAS of words and phrases in Portuguese (in Portuguese)", III Congresso Ibero-Americano de Informática na Educação Especial - CIIEE 2002 - Demonstração. Fortaleza, CE. v. 20, pp. 1 - 10, 2002.

CORADINE, L. C.; TAVARES, O. L.; ALBUQUERQUE, F. C.; RIBEIRO, M. N.; BREDA, W. L.; CALADO, I. A. A. R.; SMARSARO, A. D. "Falibras System: A virtual interpreter as a pedagogical tool to support the education of deaf people", VII Congresso Iberoamericano de Informática Educativa Especial, 2007, Mar del PlataArgentina. v. 1. pp. 1-10., 2007.

COSTA, L. S. M.; ALMEIDA, R. C. N.; MAYWORN, M. C.; ALVES, P.T.F.; BULHOES, P. A. M.; PINHEIRO, V. M. "O atendimento em saúde através do olhar da pessoa surda: avaliação e propostas" Revista da Sociedade Brasileira de Clínica Médica, v. 7, pp. 166-170, 2009.

FOLKINS, A.; SADLER, G. R.; KO, C.; BRANZ, P.; MARSH, S.; BOVEE, M. "Improving the deaf community's access to prostate and testicular cancer information: a survey study", BMC Public Health, 2005, pp. 63.

FRANCO; N. M.; BRITO, P. H. S.; CORADINE, L. C. "FALIBRAS-WEB: Accessibility of deaf people on the web in LIBRAS using collaborative design" (in Portuguese), XVIII Conferência Internacional sobre Informática na Educação - TISE 2013. Vol. 1, no.1, pp. 334-342, 2013.

QUADROS, R. M.; SCHIMIEDT, L. P. "Idéias para ensinar português para alunos surdos", MEC, pp. 120, 2006.

TAYLOR, R. N.; Medvidovic, N.; DASHOFY, E. M. "Software architecture: foundations, theory, and practice". Wiley Publishing, 2009. 